\title{
A importância da participação popular na análise de impacto regulatório pelas agências reguladoras federais brasileiras*
}

\section{The importance of popular participation in regulatory impact analysis by Brazilian federal regulatory agencies}

\author{
Emerson Gabardo** \\ Mateus Domingues Graner***
}

* Artigo recebido em 13 de julho de 2020 e aprovado em 4 de agosto de 2020. DOI: http://dx.doi. org/10.12660/rda.v279.2020.82965.

** Pontifícia Universidade Católica do Paraná, Curitiba, PR, Brasil. E-mail: emerson.gabardo.br@ gmail.com

Professor titular de direito administrativo da Pontifícia Universidade Católica do Paraná. Professor associado de direito administrativo da Universidade Federal do Paraná. Professor visitante sênior no J. W. Peltason Center for the Study of Democracy at University of California (EUA, 2020). Pós-doutorado em direito público comparado pela Fordham University School of Law (EUA, 2013). Doutor em direito do estado pela UFPR, com estágio de doutoramento na Universidade Clássica de Lisboa. Mestre em direito do estado também pela UFPR. Diretor executivo do Núcleo de Investigações Constitucionais (Ninc) da Universidade Federal do Paraná. Membro do Conselho Editorial da Editora Fórum, da Editora Íthala e da Editora Contracorrente.

*** Universidade Federal do Paraná, Curitiba, PR, Brasil. E-mail: granermateus@gmail.com Mestrando no Programa de Pós-graduação em Direito da Universidade Federal do Paraná. Membro do Instituto Paranaense de Direito Administrativo (IPDA). Advogado. 


\section{RESUMO}

O trabalho busca apresentar o contexto do surgimento da análise de impacto regulatório (AIR) e sua gradativa implementação nas agências reguladoras federais no Brasil, especialmente quanto às formas e ao momento da participação popular. Apresenta considerações críticas em relação à atual regulamentação geral e em relação às normas internas de cada agência reguladora. Sugere propostas para uma melhor participação popular no procedimento de AIR, a fim de superar o déficit democrático, aprimorar a qualidade regulatória em busca de satisfazer o interesse público, contribuir para a prestação de um serviço adequado, consagrar os objetivos de um estado social, bem como contribuir para que a decisão regulatória seja mais eficiente, coerente, tenha maior previsibilidade, transparência e possibilidade de controle.

\section{PALAVRAS-CHAVE}

Análise de impacto regulatório - agências reguladoras - participação popular - qualidade regulatória - déficit democrático

\section{ABSTRACT}

The article seeks to present the context of the emergence of regulatory impact analysis (RIA) and its gradual implementation in Brazilian federal regulatory agencies, more precisely, aspects of popular participation. It presents critical considerations regarding the current regulation and specifically each regulatory agency. It suggests proposals for better popular participation in the RIA, in order to overcome the democratic deficit, improve regulatory quality, satisfy the public interest, provide an adequate service and enshrine the objectives of a Social State, as well as contribute to an efficient, coherent, greater predictability, transparency and possibility of control of the regulatory decision.

\section{KEYWORDS}

Regulatory impact analysis - regulatory agencies - popular participation - regulatory quality - democratic déficit 


\section{Introdução}

As origens e causas da intervenção do Estado na economia a partir do século XIX podem ser entendidas por diferentes visões ideológicas. De todo modo, o Estado interventor surge em um primeiro momento para fomentar o crescimento, ordenar a atividade financeira, prestar serviços públicos e, principalmente, para controlar a competição e o abuso de poder do mercado. Em um segundo momento, início do século XX, nasce a ideia de estado providência, com a implementação de medidas mais protetivas aos cidadãos e com a noção de prestações positivas. O estado social, identificável a partir da década de 1950, é caracterizado pelo seu sistema econômico capitalista, ainda que com influências socialistas, por um regime econômico intervencionista e por um modelo de bem-estar social. ${ }^{1}$

Neste cenário, a cultura que há muito tempo impera (mas paulatinamente engatinha passos para mudar) é a de "regular primeiro, perguntar depois". Ocorre que, sem um efetivo diálogo com a sociedade civil, há grandes riscos de a regulação acabar sendo um obstáculo ao bem-estar social e econômico, criando barreiras muitas vezes desnecessárias, dificultando a inovação e a concorrência. As decisões das agências reguladoras, que serão normatizadas, não são tomadas pelos representantes eleitos pelo povo, no modelo de democracia representativa. São feitas por dirigentes indicados pelo governo. Daí parcial o déficit democrático e a necessidade de a participação popular mitigar esta falta de legitimidade. ${ }^{2}$

O presente artigo tem por objetivo investigar a participação popular, por meio das audiências e consultas públicas, no procedimento administrativo de análise de impacto regulatório (AIR) na experiência brasileira das agências reguladoras federais. ${ }^{3}$ Em síntese, a AIR engloba as seguintes fases: problema

1 GABARDO, Emerson. Mecanismos de intervención del Estado en Brasil, postmodernidad y la cuestión de la subsidiariedad. Revista Eurolatinoamericana de Derecho Administrativo, Santa Fe, v. 1, n. 2, p. 60-62, jul./dez. 2014. Para um maior aprofundamento das causas e origens da intervenção do Estado na economia, ver: MOREIRA, Vital. A ordem jurídica do capitalismo. Coimbra: Centelho, 1978 e GRAU, Eros Roberto. A ordem econômica na Constituição de 1988. 14. ed. São Paulo: Malheiros, 2010.

2 DUARTE JUNIOR, Ricardo César Ferreira. A legitimidade do estado regulador brasileiro: uma análise democrática. A\&C Revista de Direito Administrativo \& Constitucional, Belo Horizonte, a. 11, n. 43, p. 136, jan./mar. 2011.

3 Para um estudo sobre os conselhos consultivos nas agências reguladoras, outra forma de participação popular, ver: TEIXEIRA, Albano Busato; BITENCOURT, Caroline Muller. Os conselhos de participação popular como instrumento de legitimação das decisões das agências reguladoras. Revista Eletrônica da Procuradoria-Geral do Estado do Rio de Janeiro - PGE-RJ, Rio de Janeiro, v. 2, n. 2, maio/ago. 2019. 
(compreendendo suas causas e consequências), as alternativas possíveis (mapeando as soluções) e a comparação das opções regulatórias (analisando os impactos de cada uma). A finalidade é dar as orientações técnicas na tomada de decisão pelo Estado para que a regulação seja mais eficiente, tenha qualidade melhor, gere mais confiança pelos regulados, dê mais previsibilidade, transparência e legitimidade. No item 2 será apresentado inicialmente o contexto de surgimento da AIR e sua implementação, expondo suas características gerais. Em seguida, no item 3, analisar-se-á criticamente a forma desta participação e como é possível aprimorá-la, a fim de que possa efetivamente propiciar a democratização da administração pública indireta por meio de mecanismos consensuais. Na conclusão serão apontadas as agências reguladoras que demonstram avanços na superação do déficit democrático, bem como as que necessitam de maior aprimoramento. ${ }^{4}$

\section{Breves considerações sobre o contexto brasileiro e características gerais}

Antes de investigar o procedimento de AIR propriamente, é necessário situar o contexto e os pressupostos que limitam as conclusões a serem desenvolvidas. No Brasil, a origem da prática regulatória pela AIR pode ser atribuída à iniciativa do governo federal quando da criação do Programa de Fortalecimento da Capacidade Institucional para Gestão em Regulação (PRO-REG), instituído pelo Decreto no 6.602, de 16 de março de 2007, com a finalidade de arquitetar um mecanismo institucional para aprimorar a qualidade da regulação federal. ${ }^{5}$

4 Neste trabalho a expressão "participação popular" significa a participação dos cidadãos na atuação administrativa. Embora alguns autores diferenciem "participação popular", "participação popular na administração" e "participação administrativa", a expressão será utilizada indistintamente. SANTOS, Fábio Gomes dos. Participação na administração como direito fundamental. Revista Digital de Direito Administrativo, v. 1, n. 2, p. 440-442, 2014.

5 Em 2003, o governo criou o Grupo de Trabalho Interministerial (GT Interministerial) com a finalidade de avaliar o papel das agências reguladoras no atual arranjo institucional brasileiro, que culminou com o Projeto de Lei $n^{\text {o } 3.337 / 200, ~ t e n d o ~ s i d o ~ r e t i r a d o ~ p e l o ~ p r o ́ p r i o ~ P o d e r ~}$ Executivo e reapresentado como Projeto de Lei do Senado no 52 de 2013 que posteriormente foi aprovado como a Lei das Agências Reguladoras (Lei n⿳o 13.848 de 25/06/2019). No entanto, à época não existia um programa articulado de melhoria regulatória, por isso será considerado origem mais próxima o PRO-REG em 2008. Para um maior aprofundamento quanto às origens da AIR, ver: ALBUQUERQUE, Kélvia. A visão da Secretaria de Gestão do Ministério do Planejamento, Orçamento e Gestão. In: PROENÇA, Jadir Dias; DA COSTA, Patrícia Vieira; MONTAGNER, Paula (Org.). Desafios da regulação no Brasil. Brasília: Enap, 2006. p. 91. 
As agências reguladoras tal como conhecidas hoje no Brasil foram surgindo na década de 1990, após a extinção total ou parcial do monopólio estatal de alguns serviços públicos e de outras atividades consideradas sensíveis na vida da sociedade (produção cultural, uso da água e outros setores), com a consequente transferência total ou parcial destas atividades econômicas ao setor privado (mediante concessões, permissões ou autorizações). ${ }^{6}$ Por isso, às agências reguladoras foi conferido relativo grau de autonomia e independência, a fim de que pudessem criar um ambiente regulatório que equilibrasse os interesses do Estado, cidadãos e dos agentes econômicos de cada setor. ${ }^{7}$

De 2008 a 2016 o PRO-REG foi responsável por difundir e centralizar estudos no que tange à AIR, como projetos-piloto em seis agências reguladoras: Agência Nacional de Cinema (Ancine), Agência Nacional de Energia Elétrica (Aneel), Agência Nacional do Petróleo, Gás Natural e Biocombustíveis (ANP), Agência Nacional de Saúde Suplementar (ANS), Agência Nacional de Transportes Aquaviários (Antaq) e Agência Nacional de Vigilância Sanitária (Anvisa). ${ }^{8}$

Conforme o Relatório Final de 2013 do PRO-REG, o diagnóstico foi bastante negativo. De modo geral, apontou-se a ausência de cultura de análise de impacto regulatório (não havia mentalidade de gestão e poucas pessoas eram capacitadas para tratar de impacto regulatório nas agências), bem como a necessidade de melhorar o processo decisório e a metodologia de análise. Em suma, não havia institucionalização da AIR como ferramenta de melhoria da qualidade regulatória. ${ }^{9}$

6 MEDAUAR, Odete. Direito administrativo moderno. 21. ed. Belo Horizonte: Fórum, 2018, p. 63. Contudo, no direito brasileiro houve entidades com função reguladora, ainda que sem a denominação de agências, desde o início do século XX; ver: DI PIETRO, Maria Sylvia Zanella. Direito administrativo. 32. ed. Rio de Janeiro: Forense, 2019. p. 1057.

7 GUERRA, Sérgio. Direito administrativo e a nova hermenêutica: uma releitura do modelo regulatório brasileiro. Revista de Direito Administrativo, Rio de Janeiro, v. 243, p. 200, jan. 2006. Disponível em: <http://bibliotecadigital.fgv.br/ojs/index.php/rda/article/view/42559>. Acesso em: 9 jul. 2020.

8 PRESIDÊNCIA DA REPÚBLICA. Casa Civil. Histórico do PRO-REG. Disponível em: <www. gov.br/casacivil/pt-br/assuntos/governanca/regulacao/sistema-regulatorio-brasileiro/histo rico-do-pro-reg>. Acesso em: 29 maio 2020. Para mais detalhes, ver: PRESIDÊNCIA DA REPÚBLICA. Casa Civil. Boletim PRO-REG. out. 2012. Disponível em: <www.gov.br/casacivil/ pt-br/assuntos/governanca/regulacao/documentos/biblioteca-nacional/2012/boletim-pro-reg1o-semestre-de-2012>. Acesso em: 29 maio 2020. Também, PROENÇA, Jadir Dias; PAULO, Carla Beatriz (Org.). Experiências exitosas em regulação na América Latina e Caribe. Brasília: Alia Opera, 2012.

9 MARTINS, Humberto Falcão. Diagnóstico do processo de formulação e análise de políticas públicas em mercados regulados. Relatório final. Casa Civil da Presidência da República. Subchefia de 
Faz-se importante frisar as 12 diretrizes do Conselho Sobre Política Regulatória e Governança da OCDE, em 2012, recomendadas para todos os países-membros, com disposições específicas sobre a análise de impacto regulatório, ${ }^{10}$ pois em 2015 o Tribunal de Contas da União (TCU) recomendou

Análise e Acompanhamento de Políticas Governamentais. Programa de Fortalecimento da Capacidade Institucional para a Gestão em Regulação. p. 40-57. Disponível em: <www.gov. $\mathrm{br} / \mathrm{casacivil} / \mathrm{pt}$-br/assuntos/governanca/regulacao/documentos/biblioteca-nacional/2013/ diagnostico-do-processo-de-formulacao-e-analise-de-politicas-publicas-em-mercadosregulados-1>. Acesso em: 29 maio 2020.

10 "I. RECOMENDA aos membros: 1. Assumir o compromisso no mais alto nível político com uma política explícita de qualidade regulatória para o governo como um todo. A política deve ter objetivos claros e estruturas para a implementação que assegurem que, se a regulação for usada, os benefícios econômicos, sociais e ambientais justifiquem os custos, os efeitos distributivos sejam considerados e os benefícios líquidos maximizados. 2. Respeitar os princípios de um governo aberto, incluindo transparência e participação no processo regulatório para garantir que a regulação sirva ao interesse público e para que seja informado das necessidades legítimas dos interessados e das partes afetadas pela regulação. Isto inclui a oferta de canais efetivos (incluindo online), para que o público possa contribuir para o processo de preparação de propostas regulatórias e para a qualidade da análise técnica. Os governos devem assegurar que regulações sejam compreensíveis e claras e que as partes possam facilmente compreender seus direitos e obrigações. 3. Estabelecer mecanismos e instituições para supervisionar ativamente os procedimentos da política regulatória e seus objetivos, apoiar e implementar a política regulatória, e, assim, promover a qualidade regulatória. 4. Integrar a Avaliação do Impacto Regulatório (AIR) desde os estágios iniciais do processo de políticas para a formulação de novas propostas de regulação. Identificar claramente os objetivos da política, e avaliar se a regulação é necessária e como ela pode ser mais efetiva e eficiente na consecução desses objetivos. Considerar outros meios de regulação e identificar os trade offs das diferentes abordagens analisadas para escolher a melhor alternativa. 5. Conduzir programas sistemáticos de revisão do estoque regulatório em relação a objetivos que sejam claramente definidos pela política, incluindo considerações de custos e benefícios, para assegurar que as regulações estejam atualizadas, seus custos justificados, efetivos e consistentes, e almejem os objetivos pretendidos. 6. Publicar regularmente relatórios sobre o desempenho da política regulatória, dos programas de reforma, bem como das autoridades públicas responsáveis pela aplicação das regulações. Esses relatórios devem incluir informações sobre como instrumentos regulatórios, tais como a Análise de Impacto Regulatório (AIR), práticas de consulta pública e revisões de regulações existentes funcionam na prática. 7. Desenvolver uma política consistente capaz de abranger o papel e as funções das agências reguladoras, a fim de proporcionar maior confiança de que as decisões regulatórias sejam tomadas de maneira objetiva, imparcial e consistente, sem conflito de interesse ou influência indevida. 8. Assegurar a efetividade dos sistemas de revisão da legalidade e imparcialidade processual das regulações, bem como das decisões tomadas pelos órgãos competentes na aplicação de sanções regulatórias. Garantir que os cidadãos e as empresas tenham acesso a estes sistemas de revisão a um custo razoável e recebam as decisões tempestivamente. 9. Aplicar, conforme apropriado, a avaliação de riscos, gestão de riscos e estratégias de comunicação de risco para a concepção e implementação das regulações para garantir que a regulação seja direcionada e efetiva. Os reguladores devem avaliar os efeitos da regulação e devem elaborar estratégias para implementação responsiva e enforcement. 10. Promover sempre que necessário a coerência regulatória através de mecanismos de coordenação entre os níveis supranacional, nacional e subnacional do governo. Identificar questões regulatórias transversais em todos os níveis do governo, para promover a coerência entre as abordagens regulatórias e evitar a duplicação ou conflito de normas. 11. Fomentar o desenvolvimento da capacidade de gestão e desempenho regulatório nos níveis subnacionais 
a adoção destas boas práticas da OCDE às agências reguladoras (Tomada de Contas no 031.996/2013-2). Na oportunidade, o TCU apontou que: (i) na maioria das agências a AIR ainda não era obrigatória; (ii) também praticamente não havia normativos internos para o uso da ferramenta; e (iii) consultas públicas não eram obrigatórias em todas as agências. ${ }^{11}$

A partir de maio de 2016, a coordenação da agenda foi redirecionada do PRO-REG para a Subchefia de Análise e Acompanhamento de Políticas Governamentais (SAG) da Casa Civil, Presidência da República e, em conjunto com outros ministérios, desenvolveu-se o PL nº 6.621/2016, com disposições relativas à AIR, que posteriormente foram aprovadas na recente Lei no 13.848 de 2019 (Lei das Agências Reguladoras). Ademais, cerca de dois anos depois da recomendação do TCU, em 2017, a SAG publicou um mapeamento do estado das AIR nas agências reguladoras e, considerando o objeto deste trabalho, destacam-se os seguintes aspectos, conforme a tabela seguinte. ${ }^{12}$

de governo. 12. Considerar no desenvolvimento de medidas regulatórias, todos os padrões internacionais relevantes e as estruturas de cooperação na mesma área e, quando apropriado, seus possíveis efeitos sobre as partes que estejam fora da sua jurisdição." OCDE. Recomendação do Conselho sobre politica regulatória e governança. 2012. Disponível em: <www.oecd.org/gov/ regulatory-policy/Recommendation\%20PR\%20with\%20cover.pdf $>$. Acesso em: 29 maio 2020.

11 BRASIL. TCU no 031.996/2013-2. p. 22. Disponível em: <www.gov.br/casacivil/pt-br/assuntos/ governanca/regulacao/documentos/biblioteca-nacional/2013/relatorio-de-auditoria-opera cional-das-agencias-reguladoras-de-infraestrutura>. Acesso em: 30 maio 2020.

12 O material foi produzido após diversas reuniões com representantes das agências reguladoras, bem como a partir das respostas de um questionário enviado a elas. As perguntas abordavam a abrangência da realização da AIR, base legal (se existente), previsão de excepcionalidade à realização da AIR, padronização interna (guia ou orientação interna), metodologia, integração com o processo decisório, participação social e transparência, governança, monitoramento e AIR ex post, disponibilização de dados, capacitação, decisão pela não regulação, resistência interna e casos emblemáticos de AIR já realizados em cada agência (PRESIDÊNCIA DA REPÚBLICA. Casa Civil. Nota Técnica no 4/2017/AESP/SAG/CC-PR. Disponível em: <www. gov.br/casacivil/pt-br/assuntos/governanca/regulacao/boas-praticas-regulatorias/consultapublica/consulta-publica-001-2017-diretrizes-e-guia-air-pasta/abertura/documentacao-produ zida-para-construcao-das-diretrizes-gerais-e-do-guia-air/nota-tecnica-consulta-publica-0012017.pdf>. Acesso em: 30 maio 2020). 
Tabela 1

Mapeamento das Agências Reguladoras (2017)

\begin{tabular}{|c|c|c|c|c|c|c|c|c|c|c|}
\hline & 㫐 & 离崖 & 宏 & 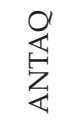 & 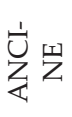 & 岕 & 艺 & 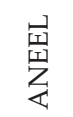 & 公 & 岁 \\
\hline Utilização & $x$ & $x$ & $x$ & $x$ & $x$ & $x$ & $x$ & $x$ & $x$ & $x$ \\
\hline Início & 2009 & 2013 & 2013 & 2015 & 2013 & 2012 & 2013 & 2011 & 2010 & 2015 \\
\hline Obrigatoriedade & $X$ & $x$ & $x$ & & & $x$ & & $x$ & $x$ & \\
\hline Normas internas & $X$ & $x$ & $x$ & $x$ & $x$ & & & $x$ & $x$ & \\
\hline $\begin{array}{l}\text { Consulta externa } \\
\text { após conclusão }\end{array}$ & $X$ & $X$ & $X$ & $x$ & $x$ & $x$ & $x$ & $\mathrm{X}$ & $X$ & $X$ \\
\hline $\begin{array}{l}\text { Consulta externa } \\
\text { antes da conclusão }\end{array}$ & $X$ & $X$ & & & & & & $x$ & & \\
\hline $\begin{array}{l}\text { Disponibilidade } \\
\text { de dados }\end{array}$ & & $X$ & & & & & & & X & \\
\hline
\end{tabular}

Fonte: Elaboração própria.

A partir dos dados obtidos em 2017, observa-se que a maioria das agências (seis entre 10) passou a considerar obrigatória a realização da AIR. Normas internas foram criadas também em grande parte das agências reguladoras (sete entre 10).

Outro ponto é que, de modo geral, as AIRs são disponibilizadas para o público apenas após a conclusão da minuta de ato normativo, por meio de audiência de consulta pública. Como se verá adiante, advêm inúmeros benefícios ao se propiciar a discussão com a sociedade civil quando efetivamente estão sendo avaliadas as opções e impactos (não apenas após a minuta, o que limita em muito as sugestões e críticas). Com efeito, uma decorrência disso é a percepção pelas agências reguladoras de que não possuem uma disponibilidade adequada de dados - entendida como o acesso, a possibilidade de solicitá-los e a capacidade de organizá-los e tratá-los. ${ }^{13}$

13 Ibid. 
$O$ referido trabalho da SAG, originalmente direcionado para ser um regulamento geral de AIR, foi transformado em dois documentos de grande peso: "Guia AIR" e "Diretrizes gerais e guia orientativo para elaboração de análise de impacto regulatório - AIR", conforme será exposto adiante com mais detalhes. Ambos foram objeto de Consulta Pública em 2017, contando com ampla participação da sociedade: 538 contribuições, sendo acatadas 105 destas (o equivalente a $20 \%$ ). ${ }^{14}$

No mesmo sentido, o Decreto n⿳9 9.203, de 22 de novembro de 2017, dispôs sobre a "Política de governança da administração Pública", enfatizando que um de seus princípios é justamente a melhoria regulatória (art. 3o, IV). Mais especificamente, são diretrizes a serem perseguidas: processos decisórios orientados pelas evidências, pela conformidade legal, pela qualidade regulatória, pela desburocratização e pelo apoio à participação da sociedade (art. 4ํ, VIII); bem como a obediência das boas práticas regulatórias na edição e revisão de atos administrativos, prezando pela estabilidade e coerência do ordenamento jurídico, reforçando também a necessidade de consultas públicas sempre que convenientes (art. $4^{\circ}$, VIII e XIX).

Recentemente, a Lei no 13.848 de 2019 (Lei das Agências Reguladoras) tratou do processo decisório das agências reguladoras no capítulo I e, de forma mais genérica, da realização de análise de impacto regulatório (AIR). Em suma, delegou-se a um futuro regulamento boa parte do conteúdo e metodologia, os quesitos mínimos, os casos obrigatórios e de dispensa. Até o momento desta pesquisa, dito ato normativo não foi publicado pela Presidência da República. A operacionalização da AIR, por sua vez, foi remetida aos regimentos internos de cada agência reguladora.

Igualmente relevante foi a previsão do art. 5으 da Lei no 13.874/2019 (Lei de Liberdade Econômica), que estipulou a obrigatoriedade de análise de impacto regulatório para a administração pública em geral. $\mathrm{O}$ seu regulamento (Decreto no 10.411/2020), embora não estabeleça a obrigatoriedade da participação popular, menciona no art. 8o que poderá ocorrer "antes da decisão sobre a melhor alternativa para enfrentar o problema regulatório identificado e antes da elaboração de eventual minuta de ato normativo a ser editado".

14 PRESIDÊNCIA DA REPÚBLICA. Casa Civil. Resultado da consulta pública: diretrizes e guia AIR - 001/2017. Disponível em: <www.gov.br/casacivil/pt-br/assuntos/governanca/regu lacao/boas-praticas-regulatorias/consulta-publica/consulta-publica-001-2017-diretrizes-eguia-air-pasta/encerramento/consulta-publica-diretrizes-e-guia-air-001-2017>. Acesso em: 30 maio 2020. 
Outros dispositivos reforçam a importância da participação e dos subsídios da sociedade (art. 6º, VIII, art. 10, ambos do Decreto nº 10.411/2020).

Outro fundamento legal para a AIR no ordenamento brasileiro é o art. 20 da Lei de Introdução das Normas de Direito Brasileiro (Decreto-Lei no 4.657/1942, alterado pela 13.655/2018) que estabelece que na esfera administrativa não se decidirá com base em valores jurídicos abstratos sem que sejam consideradas as consequências práticas da decisão. O parágrafo único explicita que a motivação demonstrará a necessidade e a adequação da medida imposta ou da invalidação de ato, contrato, ajuste, processo ou norma administrativa, inclusive em face das possíveis alternativas.

Portanto, a AIR no Brasil vem sendo gradativamente institucionalizada, sobretudo pelas agências reguladoras, após a criação da PRO-REG e mais recentemente pela SAG. Foi possível identificar os primeiros esforços em 2003, avançando para sua obrigatoriedade especialmente em 2019 com a publicação da Lei das Agências Reguladoras e Lei de Liberdade Econômica (além da LINDB), até o ponto atual, em que a AIR é uma realidade. No entanto, diversos desafios ainda estão presentes e há uma urgente necessidade de aperfeiçoamento e sistematização.

Avançando para as características gerais da AIR, esta pode ser definida como um procedimento ordenado de tomada de decisão, no exercício da atividade regulatória, mediante o uso sistemático de análises sobre os possíveis efeitos de uma determinada decisão, cujas principais etapas são: (i) delimitação dos objetivos e meios, (ii) mapeamento dos prováveis impactos, (iii) análise de custos e benefícios da medida, (iv) monitoramento dos efeitos após sua implementação. ${ }^{15}$

Deste modo, almeja-se que a AIR oriente e subsidie o processo de tomada de decisão regulatória, aumentando sua eficiência, coerência, qualidade, previsibilidade, transparência, segurança jurídica e o controle judicial - além do controle de legalidade, em termos processuais, entende-se também que estes

15 VALENTE, Patrícia Rodrigues Pessôa. Avaliação de impacto regulatório: uma ferramenta à disposição do Estado. Dissertação (mestrado em direito do estado) - Faculdade de Direito, Universidade de São Paulo, São Paulo, 2010. p. 29. Acesso em: 29 maio 2020. Semelhantemente, é a definição encontrada no Guia de AIR: “Consiste num processo sistemático de análise baseado em evidências que busca avaliar, a partir da definição de um problema regulatório, os possíveis impactos das alternativas de ação disponíveis para o alcance dos objetivos pretendidos. Tem como finalidade orientar e subsidiar a tomada de decisão e, em última análise, contribuir para que as ações regulatórias sejam efetivas, eficazes e eficientes" (Presidência da República, Casa Civil, Resultado da Consulta Pública: Diretrizes e Guia AIR 001/2017, op. cit.). 
atos administrativos são sindicáveis pelo Poder Judiciário, estando sujeitos à regra da proporcionalidade (necessidade, adequação e proporcionalidade em sentido estrito). ${ }^{16}$

Apesar de parecer óbvio, é importante destacar que a AIR não pode ser concebida como um mero formulário ou apenas uma justificativa formal de determinada escolha ou uma mera exposição de motivos. As "Diretrizes gerais e roteiro analítico" propõem alguns elementos mínimos, tais como: (i) sumário executivo; (ii) identificação do problema regulatório que se pretende solucionar, possíveis causas e extensão; (iii) identificação dos atores ou grupos afetados pelo problema; (iv) base legal que ampara a atuação da agência sobre o tema; (v) definição dos objetivos; (vi) descrição das possíveis alternativas, inclusive a opção de não ação; (vii) exposição dos possíveis impactos das alternativas; (viii) comparação das alternativas; (ix) descrição da estratégia para implementação da alternativa sugerida, formas de monitoramento e fiscalização, bem como da necessidade ou não de alteração ou revogação de normas em vigor; $(x)$ considerações referentes às informações, contribuições e manifestações recebidas para a elaboração da AIR nos processos de participação social ou demais subsídios; e (xi) dados dos responsáveis pela AIR. ${ }^{17}$

Estes requisitos mínimos, embora não vinculantes, são relevantes, pois aumentam o ônus argumentativo de motivação da agência reguladora para tomar uma decisão, a qual tem profundo impacto na sociedade. Por isso, a AIR é uma importante ferramenta para que a administração pública indique os fundamentos de fato e de direito de suas decisões. Outro aspecto muito importante é que a AIR facilita em muito uma posterior avaliação de determinada regulação e seus impactos, na medida em que organiza as informações para uma futura comparação daquilo que foi previsto e do que efetivamente ocorreu. ${ }^{18}$

16 Para um maior aprofundamento: ALEXY, Robert. Teoria dos direitos fundamentais. 2. ed. Tradução de Virgílio Afonso da Silva. São Paulo: Malheiros, 2014. p. 85-143; BARCELLOS, Ana Paula de. Ponderação, racionalidade e atividade jurisdicional. Rio de Janeiro: Renovar, 2005. p. 49-75, 91-145.

17 Presidência da República, Casa Civil, Resultado da Consulta Pública: Diretrizes e Guia AIR 001/2017. op. cit.

18 Ao sugerir quais medidas o Congresso Norte-Americano (EUA) poderia adotar para aprimorar a qualidade regulatória, Cary Coglianese cita que uma AIR bem desenvolvida é fundamental para que as agências possam realizar a avaliação de uma norma regulatória (COGLIANESE, Cary. Improving regulatory analysis at independent agencies. Revista de Direito Administrativo, Rio de Janeiro, v. 277, n. 3, p. 40, nov. 2018. Disponível em: <http://bibliotecadigital.fgv.br/ojs/ index.php/rda/article/view/77675/74640>. Acesso em: 9 jul. 2020. 
A AIR tampouco é a decisão em si, mas uma ferramenta de melhoria da qualidade regulatória. A competência decisória é atribuída ao órgão colegiado de cada agência, conforme o art. 7o da Lei das Agências Reguladoras. No mesmo sentido, as "Diretrizes gerais e roteiro analítico" apontam a ausência de vinculação da AIR, porém as decisões que sejam a ela contrárias deverão ser fundamentadas. ${ }^{19}$

Por fim, em que pese o esforço na elaboração de diretrizes gerais e o guia prático na tentativa de uniformizar o processo (o que é desejável e não prejudica os objetos e objetivos completamente distintos de cada uma das agências reguladoras), fato é que não há homogeneidade ou padronização nos procedimentos ou elementos essenciais da AIR na grande maioria das agências regulatórias brasileiras até o presente momento. Apesar de cada autarquia possuir objetos de regulação bem distintos, não significa que não possa haver um conjunto mínimo de procedimentos em comum. De qualquer forma, há diferentes estágios de institucionalização e amadurecimento da prática da AIR em cada uma delas, bem como da intensidade de participação popular. $^{20}$

\section{Análise crítica da participação popular nos procedimentos de AIR nas agências reguladoras}

A consensualidade pode ser definida como o modo de atuação dos órgãos e entidades administrativas a partir de bases e de procedimentos que privilegiam o emprego de técnicas, métodos e instrumentos negociais, em oposição a ações impositivas e unilaterais da administração pública. ${ }^{21}$

Esta forma de atuação representa uma benéfica renovação, na medida em que contribui para aprimorar a governabilidade, propicia freios contra abusos, confere maior legitimidade e torna os comandos estatais mais

19 Ibid.

20 Para uma análise completa a partir de pesquisa empírica dos AIRs, de janeiro de 2016 até fevereiro de 2017, incluindo análise da normatização interna e casos concretos, ver a obra coletiva: INSTITUTO BRASILEIRO DE ESTUDOS DE CONCORRÊNCIA, CONSUMO E COMÉRCIO INTERNACIONAL (IBRAC). Institucionalização e prática da análise de impacto regulatório no Brasil. São Paulo: Ibrac, 2019. Edição Kindle.

21 OLIVEIRA, Gustavo Henrique Justino de. O Contrato de Gestão na administração pública brasileira. Tese (doutorado) - Faculdade de Direito, Universidade de São Paulo, São Paulo, 2005. p. 281. 
estáveis. ${ }^{22}$ Sobretudo em um contexto de captura político-partidária e de déficit de legitimidade democrática nas agências reguladoras, em que o governo e partidos políticos acabam nomeando dirigentes e, em troca, seus projetos de interesse são aprovados. Tal fenômeno ocorre mesmo que formalmente as agências reguladoras possuam autonomia, como mandatos fixos dos dirigentes (nomeados), entre outras regras. ${ }^{23}$

Desta forma, a participação popular na AIR se mostra como uma medida a incrementar o consensualismo na atuação administrativa, buscando alcançar os efeitos positivos em prol de uma melhor regulação que visa garantir o interesse público de forma eficiente, assim como o serviço adequado, quando se tratar de serviço público. O princípio da eficiência administrativa, insculpido no art. 37, caput, da CF, pode ser definido como o dever constitucional imposto à administração pública de utilizar os "meios mais adequados ao alcance ótimo dos objetivos estatuídos pelo direito positivo (interesse público)" ${ }^{24}$ Significa que não basta "agir regularmente sobre os trilhos da lei e na direção da finalidade subjacente à norma: é preciso optar pelos instrumentos mais adequados para atingir o ponto ótimo na atuação administrativa" ${ }^{25}$ Desta forma, almeja-se que o serviço público seja adequado (art. 175, IV, da CF), definido pelo art. $6^{\circ}, \S 1^{\circ}$, da Lei $\mathrm{n}^{\circ}$ 8.987, de 13.2.1995, como aquele que "satisfaz as condições de regularidade, continuidade, eficiência, segurança, atualidade, generalidade, cortesia na sua prestação e modicidade das tarifas".

Partindo desta perspectiva, observa-se que há agências reguladoras federais que não contam com norma interna disciplinando as hipóteses e formas de participação popular (embora obrigatória pelo art. 9o da Lei no 13.848 de 2019), há agências que possuem normativas internas e já realizaram diversas AIR e há as que possibilitam ampla participação social.

22 MOREIRA NETO, Diogo Figueiredo. Novas tendências da democracia: consenso e direito público na virada do século - o caso brasileiro. Revista Eletrônica sobre a Reforma do Estado, Salvador, n. 13, p. 2, mar./maio 2008.

23 LEAL, Rogério Gesta; RECK, Janrié Rodrigues. A regulação da contratação pública pelas agências reguladoras: limites e possibilidades. Revista digital de Derecho Administrativo, n. 19, p. 64, 1.ำ sem. 2018. Semelhantemente, Teixeira e Bitencourt, Os conselhos de participação popular como instrumento de legitimação das decisões das agências reguladoras, op. cit., p. 12-14.

24 GABARDO, Emerson; HACHEM, Daniel. Responsabilidade civil do Estado, faute du service e o princípio constitucional da eficiência administrativa. In: GUERRA, Alexandre Dartanhan de Mello; PIRES, Luis Manuel Fonseca; BENACCHIO, Marcelo (Coord.). Responsabilidade civil do Estado. São Paulo: Quartier Latin, 2010. p. 245.

25 Ibid., p. 250. 
Por um lado, o art. 9o da Lei no 13.848 de 2019 trouxe um avanço democrático para a elaboração das análises de impacto regulatório, pois até então a realização de consulta pública não era obrigatória, isto é, era uma faculdade prevista no art. 31 da Lei nํ 9.784/99 (Lei de Processo Administrativo Federal), a ser exercida quando a matéria envolvesse assunto de interesse geral e não causasse prejuízo à parte interessada.

Não obstante, o art. 9o da Lei no 13.848 de 2019 foi insuficiente. Explica-se: o texto legal determina a participação por consulta pública antes da tomada de decisão pelo conselho diretor, porém não traz uma obrigatoriedade clara para que seja no início ou durante as primeiras etapas de estudo da AIR. Isto acarreta o problema de que a consulta e audiência pública tendem a ser realizadas apenas após a minuta do ato normativo. Não se desconhece que as agências reguladoras possam criar normas internas para ir além da Lei $n^{-} 13.848$ de 2019, tanto é que o próprio art. 11 confere amplo grau de possibilidade neste sentido, mas o ponto é que há uma dependência da vontade política de cada agência.

Faz-se necessário citar as regras contidas na Lei das Agências Reguladoras que visam disciplinar as audiências públicas no procedimento de AIR, a fim de garantir a efetividade da participação popular. $\mathrm{O}$ art. 10 da Lei no 13.848 de 2019 dispõe que: (i) as agências reguladoras poderão convocar audiência pública para formação de juízo e tomada de decisão, devendo permitir a manifestação oral por quaisquer interessados em sessão pública previamente destinada a debater matéria relevante; (ii) a abertura da audiência pública deverá ser publicada no Diário Oficial da União e em outros meios de comunicação com antecedência mínima de cinco dias úteis; (iii) também deverão ser disponibilizados na internet e em local específico, com antecedência mínima de cinco dias úteis, os documentos necessários para a participação popular (se houver, o Relatório de AIR ou nota técnica e os documentos que o fundamentam).

De todo modo, transcorrido praticamente um ano da publicação da Lei no 13.848 de 2019, considerando que a vigência iniciou 90 dias após a publicação, observa-se que nem todas as agências reguladoras se adequaram à exigência legal de participação popular.

Na Anvisa, o art. 6o da Portaria no 422 de 2008 falava exatamente o que foi exposto: "A critério da Diretoria Colegiada, as minutas de atos normativos poderão ser submetidas à consulta pública, formalizada por publicação no Diário Oficial da União". Inclusive, o art. 2ํㅡ, IV, da mesma portaria definia consulta pública como "mecanismo de participação social, aberto ao público, 
realizado em prazo definido, que possibilita a manifestação escrita sobre minuta de ato normativo, documento ou assunto relevante, para subsidiar posterior decisão da Anvisa". Porém, posteriormente, a Portaria no 1.741 de 2018 revogou a Portaria o 422 de 2008 e uma das alterações foi quanto à previsão no art. 18 que recomenda "mecanismos de participação tão logo quanto possível, ainda nas fases iniciais de análise". Outra inovação foi a do art. 20, $\S 4$ 으, da Portaria no 1.741 de 2018, que estipula que a Tomada de Subsídios, para recebimento de contribuições e fontes de informação, deve ser concluída antes da minuta do possível instrumento regulatório. Portanto, no âmbito da Anvisa é possível destacar uma evolução e aprimoramento da normatização sobre a regulação, isto é, dos procedimentos para a AIR, passando de uma previsão normativa obrigatória apenas ao final, agora para desde o início do procedimento.

Da mesma forma houve um aperfeiçoamento na Aneel. Inicialmente, o art. 5o da Resolução Normativa no 540 de 2013 mencionava que a AIR deveria ser submetida à audiência pública em conjunto com o ato normativo (obrigatório) e apenas facultava a consulta pública durante a instrução do procedimento. Contudo, tal como na Anvisa, a Resolução Normativa no 798 de 2017 (que revogou a Resolução Normativa no 540 de 2013) estabeleceu no art. 5o que antes da elaboração de eventual minuta do ato normativo, a AIR deverá ser submetida à audiência pública - não só o relatório da AIR, mas também os documentos anexos.

No âmbito da ANTT, a Deliberação no 85 de 2016, que regulamenta o procedimento de AIR, parece ser um meio-termo, pois conta com recomendações (não obrigatórias) de participação popular durante a AIR e antes da construção da minuta do ato regulatório (arts. $3^{\circ}$ e $4^{\circ}$ da Deliberação no 85 de 2016).

Ao contrário da Aneel, Anvisa e ANTT, até o presente momento as demais agências reguladoras não possuem disposição normativa quanto à obrigatoriedade de participação popular antes da minuta da regulação, no máximo há uma faculdade ou recomendação que depende da vontade da própria agência.

Na Ancine, o art. 11 da Resolução de Diretoria Colegiada (RDC) № 61 de 2018 atribui a faculdade para que o responsável pela AIR faça consulta prévia ao público externo (pesquisas, questionários, oitivas, reuniões, visitas técnicas, entre outros), o que não se confunde com a Consulta e Audiência Públicas propriamente ditas - as quais serão realizadas caso haja deliberação pela Diretoria Colegiada (art. 17, RDC no 61 de 2018). 
Na Anatel, o Regimento Interno no 612 de 2013 e a Portaria n 927 de 2015 não trazem obrigatoriedade de Consulta Pública (antes ou depois da minuta), pelo contrário: sua ocorrência depende de pedido direcionado ao Conselho Diretor, o qual aprovará ou não a participação popular antes ou durante a AIR (arts. 19 a 21 da Portaria no 927 de 2015).

A ANS possui a Resolução Normativa no 242 de 2010, que trata da participação da sociedade civil, contudo o art. $4^{\circ}$ da mencionada resolução restringe o debate ou recebimento de sugestões apenas para o momento em que há minuta de ato normativo, valendo também a mesma crítica feita inicialmente. No mesmo sentido, o art. 15 da Resolução Administrativa no 49 de 2012.

A Antaq conta com previsão no Regimento Interno (art. 52, II, da Resolução no 3.585 de 2014), porém é extremamente vaga e praticamente não há parâmetros ou até mesmo obrigatoriedade. Atualmente, tramita a Audiência Pública no 05/2020-Antaq, com o objetivo de receber contribuições da sociedade civil a fim de criar norma específica para a realização de AIR e Avaliação de Resultado Regulatório (ARR).

A ANAC, por meio do art. 2ํ, § 3으, da Instrução Normativa no 61 de 2012, timidamente menciona que o formulário da AIR deve ser apresentado nas consultas e audiências públicas. Entretanto, não trata das hipóteses obrigatórias ou o momento em que a participação deverá ou poderá ocorrer.

Situação muito mais problemática é a da ANP. Conforme a mencionada Tabela de 2017, até há notícia de AIR na ANP, como foi o grupo de trabalho criado para realizar a análise de impacto regulatório sobre "requalificação de recipientes transportáveis de aço para GLP” (Portaria ANP no 255/2013). Não obstante, ainda não há norma interna que regulamente o tema, muito menos em termos de consulta e audiências públicas. ${ }^{26}$

Semelhantemente, a ANA é uma das agências mais atrasadas em termos de prática e institucionalização da AIR. Todavia, não possui norma ou obrigatoriedade por regulamento interno. A necessidade de avanços inclusive foi objeto de auditoria da CGU, em 2018, oportunidade em que se verificou a utilização de apenas uma AIR (sobre inspeção especial de segurança de barragens), não sendo identificados manuais, guias ou sequer consultas externas para a regulação do setor. ${ }^{27}$

26 ANP. Análise de impacto regulatório em discussão na ANP. Disponível em: <www.anp.gov.br/ noticias/5486-impacto-relatorio-discussao-anp>. Acesso em: 31 maio 2020.

27 Ministério da Transparência e Controladoria-Geral da União. Avaliação da implementação da análise de impacto regulatório na Agência Nacional de Águas - ANA. 2018. Disponível em: $<$ https://auditoria.cgu.gov.br/download/11385.pdf>. Acesso em: 31 maio 2020. 
De forma geral, a participação popular é realizada no final do procedimento de AIR, na fase em que já há o relatório, o qual é submetido para consulta ou audiência pública, em conjunto com a minuta da regulação. Deste modo, as sugestões e contribuições versam muito mais sobre a redação do texto do que propriamente sobre as opções ou os impactos que levaram a agência a escolher determinado caminho. Em outras palavras, a participação popular não acaba debatendo o modelo de intervenção, mas a tendência é que se limite a ajustes pontuais sobre uma escolha já pré-concebida. Conforme concluiu o Ibrac, após profunda pesquisa empírica quanto às AIR das agências reguladoras federais até 2017 , “as modificações constatadas após a realização do procedimento de participação social sempre se referiam à minuta do regulamento e quase nunca do relatório da AIR" ${ }^{28}$

Por isso, tão importante quanto a própria realização da consulta ou audiência pública, é a necessidade de que a participação popular ocorra no momento em que efetivamente as opções e possíveis soluções estão sendo debatidas, isto é, no início ou durante a AIR, mas antes da minuta do ato normativo que se pretende construir $^{29}$ (quando não for o caso de não regulação, evidentemente), tal como agora previsto no art. 8o do Decreto no 10.411/2020 (regulamento da AIR no âmbito da Lei de Liberdade Econômica). Desta forma, a participação popular poderá ocasionar sugestões construtivas e de repente até apontar outra solução.

Se o cidadão tiver condições efetivas de participar no processo da administração pública, então é possível reduzir o déficit democrático nas agências reguladoras, pois o conceito de democracia não está limitado à função de eleitor. Contudo, as agências reguladoras têm o dever de propiciar condições efetivas de participação, sob pena de o ato normativo carecer de legitimidade e até de invalidade do ato. ${ }^{30}$

28 Ibrac, Institucionalização e prática da Análise de Impacto Regulatório no Brasil, op. cit. Posição 6264.

29 Neste sentido, o Ibrac já propunha como sugestão para aperfeiçoamento da prática da AIR "a realização de consulta pública para discutir unicamente o resultado da AIR e as alternativas identificadas, sem disponibilizar ainda a minuta do regulamento proposto" (Ibid., posição 6941).

30 Duarte Junior, A legitimidade do estado regulador brasileiro: uma análise democrática, op. cit., p. 155-157. BRUNA, Sergio Varella. Procedimentos normativos da administração e desenvolvimento econômico. In: SALOMÃO FILHO, Calixto. Regulação e desenvolvimento. São Paulo: Malheiros, 2002. p. 259; JUSTEN FILHO. Agências reguladoras e democracia: existe um déficit democrático na "regulação independente"? In: ARAGÃO. O poder normativo das agências reguladoras. Rio de Janeiro: Forense, 2006. p. 329; SACHS, Ignacy. O Estado e os parceiros sociais: negociando um pacto de desenvolvimento. In: BRESSER-PEREIRA, L. C.; WILHEIM, Jorge; SOLA, Lourdes. Sociedade e Estado em transformação. São Paulo: Unesp, 2001. p. 232. 
A pressão exercida pela sociedade configura-se um importante fator de democratização da administração pública, contribuindo para maior transparência e, assim, controle dos atos, bem como otimização da decisão que poderá afetar significativamente a vida do país. Especialmente as audiências públicas formam uma ligação entre os interesses, propiciando debate e soluções dinâmicas, criativas e plurais, sendo o cidadão um efetivo agente e não mero espectador. A democracia é fortalecida, mediante a participação ativa na tomada de decisão. ${ }^{31}$ Afinal, "o grande desafio das agências reguladoras está em impor a efetivação dos dois princípios basilares do regime jurídico do serviço público: a universalidade e a continuidade" ${ }^{32}$

O campo da regulação, habitualmente ocupado pela imperatividade e unilateralidade, agora parece abrir-se para espaços de consensualidade. ${ }^{33}$ Este novo caminho do direito administrativo de valorizar e até privilegiar formas de atuação consensual pode ser visto em algumas agências reguladoras, durante os procedimentos de AIR, notadamente Aneel, Anvisa e ANTT, porém precisa avançar e ser implementado nas demais - sobretudo na ANA, Ancine, ANP e Antaq.

A aproximação entre administração e cidadãos é feita mediante a colaboração individual ou coletiva de sujeitos no processo administrativo, rompendo-se a noção tradicional de administração contraposta à sociedade. O processo administrativo instrumentaliza as exigências pluralistas de democracia na atuação administrativa. ${ }^{34}$

Neste sentido, um exemplo significativo é o caso da AIR elaborado pela Anvisa na atualização da regulação da rotulagem nutricional dos alimentos. Destaca-se que tal procedimento contou com um Relatório Preliminar de AIR e então um Relatório Final de AIR. Em ambos houve ampla participação popular desde o início, por meio de consultas públicas, tomada pública de subsídios, diálogos setoriais, grupos de trabalho e outras medidas. A Tomada

31 TOAZZA, Vinicius Francisco; SANTIN, Janaína Rigo. Princípio da participação, consensualismo e audiências públicas. AEC - Revista de Direito Administrativo E Constitucional, Belo Horizonte, a. 13, n. 54, p. 229, out./dez. 2013.

32 BACELLAR FILHO, Romeu Felipe. Poder normativo de entes reguladores. Revista de Direito Administrativo, Rio de Janeiro, v. 230, p. 162, out. 2002. Disponível em: <http://bibliotecadigital. fgv.br/ojs/index.php/rda/article/view/46339/45110>. Acesso em: 9 jul. 2020.

33 OLIVEIRA, Gustavo Justino de; SCHWANKA, Cristiane. A administração consensual como a nova face da administração pública no século XXI: fundamentos dogmáticos, formas de expressão e instrumentos de ação. AEC - Revista de Direito Administrativo $\mathcal{E}$ Constitucional, Belo Horizonte, a. 8, n. 32, p. 40, abr./jun. 2008.

34 MEDAUAR, Odete. Direito administrativo moderno. 21. ed. Belo Horizonte: Fórum, 2018. p. 162. 
Pública de Subsídios, por exemplo, foi aberta ao público e recebeu mais de 33 mil contribuições por escrito e 725 documentos relacionados com o documento preliminar, os quais foram utilizados para embasar o Relatório de AIR. ${ }^{35}$

O problema regulatório identificado foi a dificuldade de compreensão da rotulagem nutricional pelos consumidores brasileiros. Verificou-se que muitas das causas estavam relacionadas com lacunas e inconsistências normativas, de modo que, após análise das diversas opções, foi recomendado um modelo de rotulagem nutricional frontal semi-interpretativo em formato retangular com uma lupa para informar o alto teor de açúcares adicionados, gorduras saturadas e sódio, de modo a aperfeiçoar as regras vigentes para tabela nutricional e alegações nutricionais. ${ }^{36}$

O caso é emblemático não só por evidenciar a importância da regulação, dado que as informações nutricionais dos alimentos são de interesse de toda a sociedade, mas também porque contou com milhares de contribuições da sociedade civil, observa-se a essencialidade e relevância da democratização da administração pública. Afinal, dificilmente a Anvisa unilateralmente teria condições de captar todas as nuanças e a complexidade do tema para aperfeiçoar a atual regulação sobre rotulagem de alimentos.

E quando se diz em complexidade, não se limita apenas a pontos de vista estritamente técnicos. Pretensões hiper-racionalistas na prática podem produzir estados de coisas bem distantes do imaginado por aqueles que insistem na aproximação entre real e ideal. ${ }^{37}$ Significa que apenas uma visão técnica pode não captar como efetivamente os cidadãos veem (ou deixam de ver) as informações nutricionais, sendo benéfico que cidadãos não especialistas possam debater e apresentar suas considerações, tal como ocorreu na AIR da rotulagem de alimentos.

Nitidamente, no caso em tela se verifica que a participação popular possibilita a criação de novos direitos e a defesa daqueles já consolidados,

35 MENEGUIN, Fernando B.; SAAB, Flavio. Análise de impacto regulatório: perspectivas a partir da Lei da Liberdade Econômica. Brasília: Senado, 2020. p. 15. Disponível em: <www12.senado. leg.br/publicacoes/estudos-legislativos/tipos-de-estudos/textos-para-discussao/td271>. Acesso em: 5 jun. 2020.

36 ANVISA. Relatório de análise de impacto regulatório sobre rotulagem nutricional. Brasília, set. 2019. Gerência-Geral de Alimentos. Disponível em: <http://portal.anvisa.gov.br/documents/10181/ 3882585/\%281\%29Relat\%C3\%B3rio+de+An\%C3\%A1lise+de+Impacto+Regulat\%C3\%B3rio+so bre+Rotulagem+Nutricional/3e2c2728-b55a-4296-b5af-6c7960fd6efa>. Acesso em: 5 jun. 2020.

37 LEAL, Fernando. Análise de impacto regulatório e proporcionalidade: semelhanças estruturais, mesmos problemas reais? Revista Brasileira de Políticas Públicas, Brasília, v. 9, n. 3, p. 342, 2019. 
concretizando o princípio democrático. Não apenas isto, como servindo como elemento do estado social e democrático de direito. ${ }^{38}$

A AIR, como ferramenta de maior transparência e participação popular, tem grande potencial para efetivar o princípio da supremacia do interesse público, entendida por seus dois níveis de significação: (i) a atuação estatal não só em prol do bem-estar dos indivíduos atuais, mas também das gerações posteriores; e (ii) o interesse público entendido não somente pelos interesses nacionais, mas também os da humanidade como um todo. ${ }^{39}$

A determinação do interesse público em muito é desenvolvida por meio de diálogo, negociação, acordo, coordenação, descentralização, cooperação e colaboração. Assim, o processo de determinação do interesse público passa a ser desenvolvido a partir de uma perspectiva consensual e dialógica, a qual contrasta com a dominante perspectiva imperativa e monológica, avessa à utilização de mecanismos comunicacionais internos e externos à organização administrativa. ${ }^{40}$ Para que se ultrapasse a noção de atos unilaterais e de insegurança jurídica, é urgente "a definição de mecanismos claros de participação da sociedade nos processos, na ponderação e na valoração tecnicamente motivada". ${ }^{41}$

Portanto, embora a AIR não signifique em si uma garantia de melhora na qualidade regulatória, a necessidade de explicitação do problema, opções e resultados almejados é de extrema importância, pois este anúncio dos critérios, prioridades, metas, meios e resultados é parâmetro ao qual a agência reguladora se vincula. A participação popular nestes procedimentos administrativos potencializa em muito a persecução destes objetivos, pois amplia os distintos e plurais pontos de vista e interesses.

38 SCHIER, Adriana da Costa Ricardo; MELO, Juliane Andrea de Mendes Hey. O direito à participação popular como expressão do Estado Social e Democrático de Direito. AEC Revista de Direito Administrativo \& Constitucional, Belo Horizonte, a. 17, n. 69, p. 144, jul./set. 2017.

39 GABARDO, Emerson. O princípio da supremacia do interesse público sobre o interesse privado como fundamento do direito administrativo social. Revista de Investigações Constitucionais, Curitiba, v. 4, n. 2, p. 95-130, maio/ago. 2017. DOI: http://dx.doi.org/10.5380/rinc.v4i2.53437

40 Oliveira, Schwanka, A administração consensual como a nova face da administração pública no século XXI, op. cit. p. 318.

41 GUERRA, Sérgio. Discricionariedade, regulação e reflexividade: uma nova teoria sobre as escolhas administrativas. 3. ed. Belo Horizonte: Fórum, 2015. p. 361. 


\section{Conclusão}

É possível constatar que no âmbito das agências reguladoras federais no Brasil o paradigma "regular primeiro, perguntar depois" vem sendo gradativamente substituído pela consensualidade, por meio da participação popular nos procedimentos administrativos de análise de impacto regulatório (AIR). Afinal, o diálogo com a sociedade civil possui grande potencial para aprimorar a qualidade regulatória em busca de satisfazer o interesse público e consagrar os objetivos de um estado social. Isto porque as informações apresentadas pela população (muitas vezes desconhecidas pela administração pública) e os diferentes pontos de vista podem contribuir para que a decisão regulatória seja mais eficiente, coerente, tenha maior previsibilidade, transparência e possibilidade de controle, tanto em termos processuais como de discricionariedade, segundo a regra da proporcionalidade (necessidade, adequação e proporcionalidade em sentido estrito).

Demonstrou-se que o surgimento e a institucionalização da AIR no Brasil foram impulsionados por iniciativas do governo federal a partir de 2003 (PRO-REG e SAG), as quais foram surtindo efeitos nas agências reguladoras. Especialmente com a obrigatoriedade em 2019, mediante a publicação da Lei das Agências Reguladoras, Lei de Liberdade Econômica e nova redação da LINDB, tal procedimento administrativo passou a ser uma realidade em praticamente todas as referidas autarquias.

Apesar disso, a democratização da administração pública indireta depende de mecanismos consensuais que efetivamente permitam a participação popular na análise de impacto regulatório no momento mais adequado. Em outras palavras, tão importante quanto a própria realização da consulta ou audiência pública, é imprescindível que a participação popular ocorra no início ou durante a AIR, mas antes da minuta do ato normativo que se pretende construir (quando não for o caso de não regulação, evidentemente). Desta forma, a participação popular poderá atingir os mencionados objetivos e reduzir o déficit democrático; caso contrário, a norma que não tiver tal participação poderá ser considerada inválida. Merecem destaque a Aneel, Anvisa e ANTT pelas boas práticas e previsão normativa interna. Já a ANA, Ancine, ANP e Antaq merecem especial atenção e monitoramento, a fim de que haja um aperfeiçoamento normativo. 


\section{Referências}

ALBUQUERQUE, Kélvia. A visão da Secretaria de Gestão do Ministério do Planejamento, Orçamento e Gestão. In: PROENÇA, Jadir Dias; DA COSTA, Patrícia Vieira; MONTAGNER, Paula (Org.). Desafios da regulação no Brasil. Brasília: Enap, 2006. p. 83-104.

ALEXY, Robert. Teoria dos direitos fundamentais. 2. ed. Tradução de Virgílio Afonso da Silva. São Paulo: Malheiros, 2014.

BACELLAR FILHO, Romeu Felipe. Poder normativo de entes reguladores. Revista de Direito Administrativo, Rio de Janeiro, v. 230, p. 153-162, out. 2002. Disponível em: <http://bibliotecadigital.fgv.br/ojs/index.php/rda/article/ view/46339/45110>. Acesso em: 9 jul. 2020. DOI: http://dx.doi.org/10.12660/ rda.v230.2002.46339.

BARCELLOS, Ana Paula de. Ponderação, racionalidade e atividade jurisdicional. Rio de Janeiro: Renovar, 2005.

BRASIL. ANP. Análise de impacto regulatório em discussão na ANP. Disponível em: <www.anp.gov.br/noticias/5486-impacto-relatorio-discussao-anp>. Acesso em: 31 maio 2020.

. Anvisa. Relatório de análise de impacto regulatório sobre rotulagem nutricional. Brasília. set. 2019. Gerência-Geral de Alimentos. Disponível em: <http://portal. anvisa.gov.br/documents/10181/3882585/\%281\%29Relat\%C3\%B3rio+de+An $\%$ C3\%A1lise+de+Impacto+Regulat $\%$ C3\%B3rio+sobre+Rotulagem+Nutricion al/3e2c2728-b55a-4296-b5af-6c7960fd6efa>. Acesso em: 5 jun. 2020.

. Ministério da Transparência e Controladoria-Geral da União. Avaliação da implementação da análise de impacto regulatório na Agência Nacional de Águas - ANA. 2018. Disponível em: <https://auditoria.cgu.gov.br/download/11385. pdf>. Acesso em: 31 maio 2020.

. Presidência da República. Casa Civil. Boletim PRO-REG. out. 2012. Disponível em: <www.gov.br/casacivil/pt-br/assuntos/governanca/regulacao/ documentos/biblioteca-nacional/2012/boletim-pro-reg-1o-semestre-de-2012>. Acesso em: 29 maio 2020. 
. Presidência da República. Casa Civil. Histórico do PRO-REG. Disponível em: <www.gov.br/casacivil/pt-br/assuntos/governanca/regulacao/sistemaregulatorio-brasileiro/historico-do-pro-reg>. Acesso em: 29 maio 2020.

. Presidência da República. Casa Civil. Nota Técnica nº 4/2017/AESP/ SAG/CC-PR. Disponível em: <www.gov.br/casacivil/pt-br/assuntos/gover nanca/regulacao/boas-praticas-regulatorias/consulta-publica/consultapublica-001-2017-diretrizes-e-guia-air-pasta/abertura/documentacao-produ zida-para-construcao-das-diretrizes-gerais-e-do-guia-air/nota-tecnica-consul ta-publica-001-2017.pdf>. Acesso em: 30 maio 2020.

- Presidência da República. Casa Civil. Resultado da Consulta Pública: Diretrizes e Guia AIR - 001/2017. Disponível em: <www.gov.br/casacivil/ pt-br/assuntos/governanca/regulacao/boas-praticas-regulatorias/consultapublica/consulta-publica-001-2017-diretrizes-e-guia-air-pasta/encerramento/ consulta-publica-diretrizes-e-guia-air-001-2017>. Acesso em: 30 maio 2020.

. TCU no 031.996/2013-2. Disponível em: <www.gov.br/casacivil/ptbr/assuntos/governanca/regulacao/documentos/biblioteca-nacional/2013/ relatorio-de-auditoria-operacional-das-agencias-reguladoras-de-infraestru tura>. Acesso em: 30 maio 2020.

BRUNA, Sergio Varella. Procedimentos normativos da administração e desenvolvimento econômico. In: SALOMÃO FILHO, Calixto. Regulação e desenvolvimento. São Paulo: Malheiros, 2002. p. 231-262.

COGLIANESE, Cary. Improving regulatory analysis at independent agencies. Revista de Direito Administrativo, Rio de Janeiro, v. 277, n. 3, p. 15-47, nov. 2018. Disponível em: <http://bibliotecadigital.fgv.br/ojs/index.php/rda/article/ view/77675/74640>. Acesso em: 9 jul. 2020. DOI: http://dx.doi.org/10.12660/ rda.v277.2018.77675.

DI PIETRO, Maria Sylvia Zanella. Direito administrativo. 32. ed. Rio de Janeiro: Forense, 2019.

DUARTE JUNIOR, Ricardo César Ferreira. A legitimidade do estado regulador brasileiro: uma análise democrática. A\&C Revista de Direito Administrativo \& Constitucional, Belo Horizonte, a. 11, n. 43, p. 135-166, jan./mar. 2011. DOI: http://dx.doi.org/10.21056/aec.v11i43.231. 
GABARDO, Emerson. Mecanismos de intervención del Estado en Brasil, postmodernidad y la cuestión de la subsidiariedad. Revista Eurolatinoamericana de Derecho Administrativo, Santa Fe, v. 1, n. 2, p. 59-71, jul./dez. 2014. DOI: www.dx.doi.org/10.14409/rr.v1i2.4618.

. O princípio da supremacia do interesse público sobre o interesse privado como fundamento do direito administrativo social. Revista de Investigações Constitucionais, Curitiba, v. 4, n. 2, p. 95-130, maio/ago. 2017. DOI: http:// dx.doi.org/10.5380/rinc.v4i2.53437.

; HACHEM, Daniel. Responsabilidade civil do Estado, faute du service e o princípio constitucional da eficiência administrativa. In: GUERRA, Alexandre Dartanhan de Mello; PIRES, Luis Manuel Fonseca; BENACCHIO, Marcelo (Coord.). Responsabilidade civil do Estado. São Paulo: Quartier Latin, 2010. p. 240-292.

GRAU, Eros Roberto. A ordem econômica na Constituição de 1988. 14. ed. São Paulo: Malheiros, 2010.

GUERRA, Sérgio. Direito administrativo e a nova hermenêutica: uma releitura do modelo regulatório brasileiro. Revista de Direito Administrativo, Rio de Janeiro, v. 243, p. 168-207, jan. 2006. Disponível em: <http://bibliotecadigital.fgv.br/ojs/ index.php/rda/article/view/42559>. Acesso em: 9 jul. 2020. DOI: http://dx.doi. org/10.12660/rda.v243.2006.42559.

- Discricionariedade, regulação e reflexividade: uma nova teoria sobre as escolhas administrativas. 3. ed. Belo Horizonte: Fórum, 2015.

INSTITUTO BRASILEIRO DE ESTUDOS DE CONCORRÊNCIA, CONSUMO E COMÉRCIO INTERNACIONAL (IBRAC). Institucionalização e prática da análise de impacto regulatório no Brasil. São Paulo: Ibrac, 2019. Edição Kindle.

JUSTEN FILHO, Marçal. Agências reguladoras e democracia: existe um déficit democrático na "regulação independente"? In: ARAGÃO, Alexandre Santos de. O poder normativo das agências reguladoras. Rio de Janeiro: Forense, 2006. p. 301-332.

LEAL, Fernando. Análise de impacto regulatório e proporcionalidade: semelhanças estruturais, mesmos problemas reais? Revista Brasileira de Políticas Públicas, Brasília, v. 9, n. 3, p. 313-349, 2019. DOI: http://dx.doi.org/10.5102/ rbpp.v9i3.6278. 
LEAL, Rogério Gesta; RECK, Janriê Rodrigues. A regulação da contratação pública pelas agências reguladoras: limites e possibilidades. Revista digital de Derecho Administrativo, n. 19, p. 49-81, 1. sem. 2018. DOI: https://doi. org/10.18601/21452946.n19.05.

MARTINS, Humberto Falcão. Diagnóstico do processo de formulação e análise de políticas públicas em mercados regulados. Relatório final. Casa Civil da Presidência da República. Subchefia de Análise e Acompanhamento de Políticas Governamentais. Programa de Fortalecimento da Capacidade Institucional para a Gestão em Regulação. Disponível em: <www.gov.br/casacivil/ pt-br/assuntos/governanca/regulacao/documentos/biblioteca-nacional/2013/ diagnostico-do-processo-de-formulacao-e-analise-de-politicas-publicas-emmercados-regulados-1>. Acesso em: 29 maio 2020.

MEDAUAR, Odete. Direito administrativo moderno. 21. ed. Belo Horizonte: Fórum, 2018.

MENEGUIN, Fernando B.; SAAB, Flavio. Análise de impacto regulatório: perspectivas a partir da Lei da Liberdade Econômica. Brasília: Senado, 2020. Disponível em: <www12.senado.leg.br/publicacoes/estudos-legislativos/ tipos-de-estudos/textos-para-discussao/td271>. Acesso em: 5 jun. 2020.

MOREIRA, Vital. A ordem jurídica do capitalismo. Coimbra: Centelho, 1978.

MOREIRA NETO, Diogo Figueiredo. Novas tendências da democracia: consenso e direito público na virada do século - o caso brasileiro. Revista Eletrônica sobre a Reforma do Estado, Salvador, n. 13, p. 1-17, mar./maio 2008.

OCDE. Recomendação do Conselho sobre política regulatória e governança. 2012. Disponível em: <www.oecd.org/gov/regulatory-policy/Recommendation\%20 PR\%20with\%20cover.pdf>. Acesso em: 29 maio 2020.

OLIVEIRA, Gustavo Henrique Justino de. O contrato de gestão na administração pública brasileira. Tese (doutorado) - Faculdade de Direito, Universidade de São Paulo, São Paulo, 2005.

; SCHWANKA, Cristiane. A administração consensual como a nova face da administração pública no século XXI: fundamentos dogmáticos, formas de expressão e instrumentos de ação. AEC - Revista de Direito Administrativo $\mathcal{E}$ Constitucional, Belo Horizonte, a. 8, n. 32, p. 31-50, abr./jun. 2008. DOI: http:// dx.doi.org/10.21056/aec.v8i32.504. 
PROENÇA, Jadir Dias; PAULO, Carla Beatriz (Org.). Experiências exitosas em regulação na América Latina e Caribe. Brasília: Alia Opera, 2012.

SACHS, Ignacy. O Estado e os parceiros sociais: negociando um pacto de desenvolvimento. In: BRESSER-PEREIRA, Luiz Carlos; WILHEIM, Jorge; SOLA, Lourdes. Sociedade e Estado em transformação. São Paulo: Unesp, 2001. p. 197-217.

SANTOS, Fábio Gomes dos. Participação na administração como direito fundamental. Revista Digital de Direito Administrativo, São Paulo, v. 1, n. 2, p. 436-453, 2014. DOI: https://doi.org/10.11606/issn.2319-0558.v1i2p436-453.

SCHIER, Adriana da Costa Ricardo; MELO, Juliane Andrea de Mendes Hey. $\mathrm{O}$ direito à participação popular como expressão do estado social e democrático de direito. AEC - Revista de Direito Administrativo E Constitucional, Belo Horizonte, a. 17, n. 69, p. 127-147, jul./set. 2017. DOI: http://dx.doi. org/10.21056/aec.v17i69.825.

TEIXEIRA, Albano Busato; BITENCOURT, Caroline Muller. Os conselhos de participação popular como instrumento de legitimação das decisões das agências reguladoras. Revista Eletrônica da Procuradoria-Geral do Estado do Rio de Janeiro - PGE-RJ, Rio de Janeiro, v. 2, n. 2, p. 1-22, maio/ago. 2019.

TOAZZA, Vinicius Francisco; SANTIN, Janaína Rigo. Princípio da participação, consensualismo e audiências públicas. AEC - Revista de Direito Administrativo E Constitucional, Belo Horizonte, a. 13, n. 54, p. 207-231, out./ dez. 2013. DOI: http://dx.doi.org/10.21056/aec.v13i54.119.

VALENTE, Patrícia Rodrigues Pessôa. Avaliação de impacto regulatório: uma ferramenta à disposição do Estado. Dissertação (mestrado em direito do estado) - Faculdade de Direito, Universidade de São Paulo, São Paulo, 2010. DOI: 10.11606/D.2.2010.tde-26032012-092844. Acesso em: 29 maio 2020. 